\title{
Adrenal suppression with inhaled budesonide and fluticasone propionate given by large volume spacer to asthmatic children
}

\author{
D J Clark, R A Clark, B J Lipworth
}

\begin{abstract}
Background - The aim of this study was to compare the systemic bioactivity of inhaled budesonide (B) and fluticasone propionate $(F)$, each given by large volume spacer, on a microgram equivalent basis in asthmatic children.

Methods - Ten stable asthmatic children of mean age 11 years and forced expiratory volume in one second $\left(F E V_{1}\right) 81.6 \%$ predicted, who were receiving treatment with $\leqslant 400 \mu \mathrm{g} /$ day of inhaled corticosteroid, were studied in a placebo controlled single blind (investigator blind) randomised crossover design comparing single doses of inhaled budesonide and fluticasone propionate $400 \mu \mathrm{g}, 800 \mu \mathrm{g}$, and $1250 \mu \mathrm{g}$. Doses were given at 20.00 hours with mouth rinsing and an overnight 12 hour urine sample was collected for estimation of free cortisol and creatinine excretion.
\end{abstract}

Results - The results of overnight 12 hour urinary cortisol output (nmol/12 hours) showed suppression with all doses of fluticasone propionate (as geometric means): F400 $\mu \mathrm{g}$ (11.99), F800 $\mu \mathrm{g}$ (6.49), F1250 $\mu \mathrm{g}$ (7.00) compared with placebo (24.43), whereas budesonide caused no suppression at any dose. A comparison of the drugs showed that there were differences at $800 \mu \mathrm{g}$ and $1250 \mu \mathrm{g}$ levels for urinary cortisol: B800 $\mu$ g versus $F 800 \mu$ ( 2.65 -fold, $95 \% \mathrm{CI} 1.26$ to 5.58$)$, B1250 $\mu \mathrm{g}$ versus F1250 $\mu$ g (2.94-fold, 95\% CI 1.67 to 5.15). The results for the cortisol/creatinine ratio were similar to that of urinary cortisol, with fluticasone causing suppression at all doses and with differences between the drugs at $800 \mu \mathrm{g}$ and $1250 \mu \mathrm{g}$.

Conclusions - Single doses of inhaled fluticasone produce greater systemic bioactivity than budesonide when given by large volume spacer on a microgram equivalent basis in asthmatic children. The systemic bioactivity of fluticasone, like budesonide, is due mainly to lung bioavailability.

(Thorax 1996;51:941-943)

Keywords: asthmatic children, adrenal suppression, fluticasone propionate, budesonide, inhaled corticosteroid.
The systemic activity of inhaled corticosteroids is determined by several factors including glucocorticoid receptor potency, receptor binding affinity, plasma elimination half life, lipophilicity, and systemic tissue retention. The systemic effects of inhaled corticosteroids may arise by absorption from either the gastrointestinal tract or the lung. ${ }^{1}$ Using a large volume spacer results in approximately $20 \%$ lung deposition and less than $10 \%$ oropharyngeal deposition. ${ }^{2}$ As first pass hepatic metabolism is estimated at $99 \%$ for fluticasone propionate and $89 \%$ for budesonide, ${ }^{34}$ it is clear that, when using a large volume spacer, the main determinant of overall systemic bioavailability will be the lung bioavailability which avoids first pass hepatic metabolism for both fluticasone and budesonide. $^{1}$

Although systemic side effects from inhaled corticosteroids are not considered a problem at doses up to $400 \mu \mathrm{g} / \mathrm{day}$, it is not uncommon for asthmatic children to require higher doses to maintain control of their disease. The aim of this study was to compare the systemic bioactivity of single doses of budesonide and fluticasone propionate given by large volume spacer to asthmatic children. As far as we are aware, no dose-ranging studies have previously addressed this issue in children.

\section{Methods}

PATIENTS

Ten asthmatic children (outpatients, two girls) of mean (SD) age 11 (2.11) years (range 8-14) completed the study. The mean forced expiratory volume in one second $\left(\mathrm{FEV}_{1}\right)$ was 81.6 (6.26)\% predicted (range $72-91 \%$ predicted) and mid forced expiratory flow $\left(\mathrm{FEF}_{25-75}\right)$ was 74.8 (16.5)\% predicted. All were using inhaled corticosteroids in a dose of $\leqslant 400 \mu \mathrm{g} /$ day: beclomethasone dipropionate $200 \mu \mathrm{g}$ /day (two children), $300 \mu \mathrm{g} /$ day (one child), $400 \mu \mathrm{g} /$ day (three children); budesonide $400 \mu \mathrm{g} /$ day (two children), and fluticasone propionate 200 $\mu \mathrm{g} /$ day (two children). None had received oral corticosteroids in the preceding three months.

Both parents and children gave written informed consent. Approval for the study was obtained from the Tayside medical ethics committee for measurement of overnight 
Table 1 Geometric mean (95\% confidence intervals) 12 hour urinary free cortisol excretion and cortisol/creatinine ratios

\begin{tabular}{|c|c|c|}
\hline \multirow[b]{2}{*}{ Dose of inhaled corticosteroid ( $\mu g)$} & \multirow{2}{*}{$\begin{array}{l}\text { Urinary cortisol }(\mathrm{nmol} / 12 \mathrm{~h}) \\
\text { Fluticasone/budesonide }\end{array}$} & \multirow{2}{*}{$\begin{array}{l}\begin{array}{l}\text { Cortisol/creatinine ratio } \\
(\mathrm{nmol} / \mathrm{mmol})\end{array} \\
\text { Fluticasone/budesonide }\end{array}$} \\
\hline & & \\
\hline \multicolumn{3}{|l|}{400} \\
\hline Fluticasone & $11.99(8.47 \text { to } 16.94)^{\star}$ & $4.31(2.86 \text { to } 6.49)^{\star}$ \\
\hline Budesonide & 15.38 (9.50 to 24.75$)$ & 5.38 (3.27 to 8.85$)$ \\
\hline \multicolumn{3}{|l|}{800} \\
\hline Fluticasone & $6.49(4.58 \text { to } 9.16)^{\star \star}$ & $2.21(1.47 \text { to } 3.32)^{\star \star}$ \\
\hline Budesonide & $17.21(10.69$ to 27.54$)$ & $5.24(3.18$ to 8.61$)$ \\
\hline \multicolumn{3}{|l|}{1250} \\
\hline Fluticasone & $7.00(4.94 \text { to } 9.89)^{\star \star \star}$ & $2.26(1.50 \text { to } 3.40)^{\star \star}$ \\
\hline Budesonide & $20.53(12.76$ to 33.04$)$ & $6.57(4.00$ to 10.81$)$ \\
\hline Placebo & $24.43(17.26$ to 34.51$)$ & $8.55(5.68$ to 12.85$)$ \\
\hline
\end{tabular}

${ }^{\star} \mathrm{p}<0.05 ;{ }^{\star \star} \mathrm{p}<0.01 ;{ }^{\star \star \star} \mathrm{p}<0.001$

urinary cortisol but not plasma cortisol. All the children were continent of urine day and night.

PROTOCOL

A single blind (investigator blind) randomised (Latin square) crossover design was used. Patients were randomised to receive single inhaled doses of either placebo, budesonide (Pulmicort MDI, $50 \mu \mathrm{g}$ and $200 \mu \mathrm{g}$ per actuation, Astra Pharmaceuticals, Hertfordshire, UK), or fluticasone propionate (Flixotide MDI, $25 \mu \mathrm{g}, 50 \mu \mathrm{g}, 125 \mu \mathrm{g}$, and $250 \mu \mathrm{g}$ per actuation, Allen and Hanburys, Uxbridge, Middlesex, UK) taken in conjunction with their respective large volume spacer (Nebuhaler or Volumatic). Budesonide and fluticasone were given in identical single doses of 400 $\mu \mathrm{g}, 800 \mu \mathrm{g}$, and $1250 \mu \mathrm{g}$. A second placebo day was included one week after the last randomised treatment in order to check the reproducibility of urinary cortisol excretion between the two study days. Each study dose was taken at 20.00 hours at night with mouth rinsing, 15 minutes after the patient's usual bronchodilator treatment, with at least three days washout between each study treatment. The dose of inhaled steroid was kept constant throughout the study except for omitting it on the evening of the study day. Before taking the study drug patients emptied their bladder and collected all their overnight urine for 12 hours until 08.00 hours the following morning.

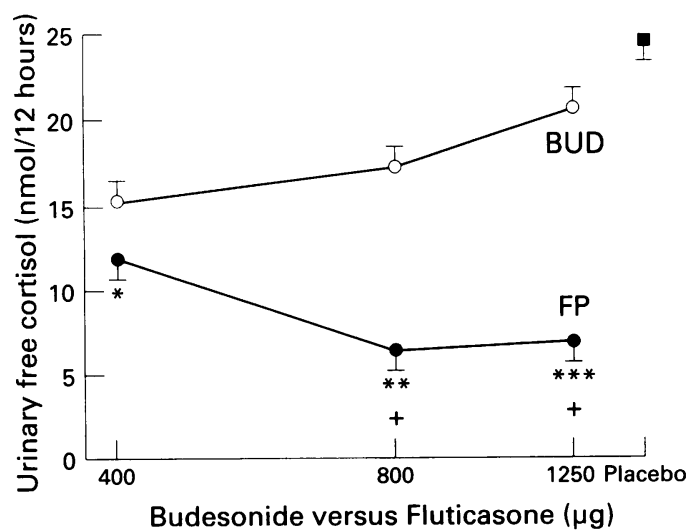

Figure 1 Geometric mean (SE) 12 hour urinary free cortisol levels with single doses of budesonide (BUD), fluticasone (FP) and placebo. Crosses denote a significant difference $(p<0.05)$ between budesonide and fluticasone at a given dose level. Asterisks denote a significant difference between the steroid dose and placebo $\left({ }^{\star} p<0.05\right.$, $\star_{*} p<0.01,{ }^{\star \star *} p<0.001$ ).
MEASUREMENTS

Overnight 12 hour urinary free cortisol excretion and creatinine excretion were measured. The urinary cortisol was measured using a commercial radioimmunoassay kit (Incstar, Wokingham, Berkshire, UK). The coefficients of variability for intra-assay and interassay analytical imprecision were $8.50 \%$ and $6.65 \%$, respectively. Urinary creatinine was measured on a Cobas-Bio autoanalyser (Roche Products Ltd, Welwyn Garden City, Hertfordshire, UK). The intra-assay and interassay coefficients of variability were $4.55 \%$ and $0.63 \%$, respectively.

STATISTICAL ANALYSIS

All data were analysed using multifactorial analysis of variance (MANOVA) and Duncan's multiple range testing with subjects, treatments, period, and doses as factors. All data were $\log$ transformed as they were not normally distributed. For comparison of the proportion of cortisol values below $10 \mathrm{nmol} / 12$ hours the $\chi^{2}$ test was used.

\section{Results}

Data for 12 hour urinary free cortisol and cortisol/creatinine ratio are given in table 1 . The overnight 12 hour urinary cortisol output (nmol/12 hours) showed suppression for all doses of fluticasone propionate compared with placebo (as fold difference from placebo with 95\% CI): F400 $\mu \mathrm{g}$ (2.04-fold, 95\% CI 1.13 to 3.36), F800 $\mu \mathrm{g}$ (3.77-fold, $95 \%$ CI 1.89 to 7.50), F1250 $\mu \mathrm{g}$ (3.49-fold, 95\% CI 1.98 to 6.15), whereas budesonide caused no suppression at any dose (fig 1). Differences were seen between the drugs at dose levels of $800 \mu \mathrm{g}$ and $1250 \mu \mathrm{g}$ for urinary cortisol: B800 $\mu \mathrm{g}$ versus F800 $\mu \mathrm{g}$ (2.65-fold, 95\% CI 1.26 to 5.58$)$, B1250 $\mu \mathrm{g}$ versus F1250 $\mu \mathrm{g}$ (2.94-fold, 95\% CI 1.67 to 5.15). The results for the cortisol/ creatinine ratio were identical to those of urinary cortisol with suppression by fluticasone at all doses and with differences between the drugs at $800 \mu \mathrm{g}$ and $1250 \mu \mathrm{g}$. The data for all three doses are also presented as individual values to show dispersion and outliers (fig 2)

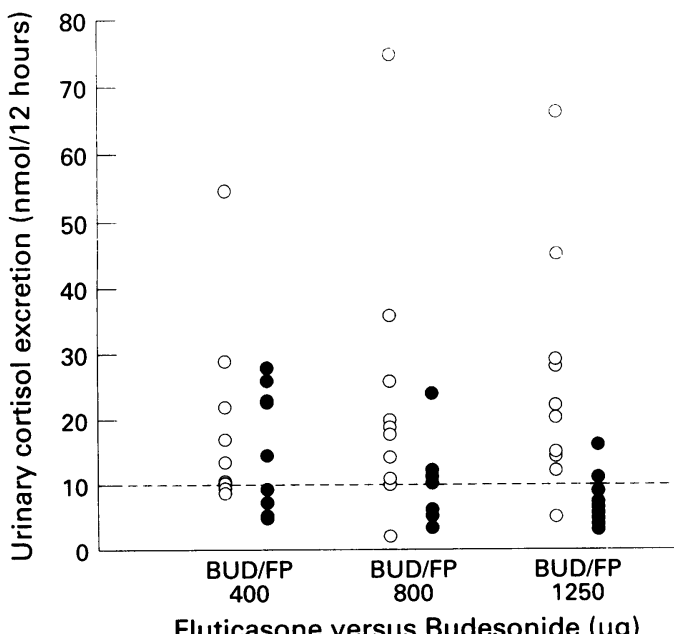

Figure 2 Individual values of urinary free cortisol for fluticasone (FP, ) and budesonide (BUD, O). Six of 30 budesonide and 18 of 30 fluticasone measurements were below 10 nmol/12 hours $(p<0.005)$. 
and show that six of 30 budesonide measurements and 18 of 30 fluticasone measurements were below $10 \mathrm{nmol} / 12$ hours ( $\mathrm{p}<0.005$ ).

There was no significant difference in urinary cortisol excretion between the two placebo days: placebo day $1(18.58 \mathrm{nmol} / 12$ hours) versus placebo day $2(18.71 \mathrm{nmol} / 12$ hours). The intrasubject coefficient of variation for the placebo days was $5.37 \%$.

\section{Discussion}

The results of this study show that, when given by large volume spacer to asthmatic children, single inhaled doses of fluticasone propionate of 400-1250 $\mathrm{\mu g}$ produce suppression of urinary cortisol compared with placebo, whereas corresponding doses of budesonide do not.

The greater systemic bioactivity of fluticasone propionate revealed by this study can be explained by its basic pharmacology. The estimates for topical glucocorticosteroid activity as assessed by the MacKenzie skin vasoconstrictor assay vary. However, it is generally accepted that fluticasone propionate is at least twice as potent as budesonide and beclomethasone dipropionate. ${ }^{56}$ Fluticasone also has a greater glucocorticoid receptor affinity than budesonide, higher lipophilicity, ${ }^{7}$ and a longer glucocorticoid/receptor complex half life. ${ }^{8}$ In adults the plasma half life of fluticasone is 14.4 hours compared with 2.3 hours for budesonide. ${ }^{9}{ }^{10}$ Interestingly, in children there is $40 \%$ greater clearance of budesonide with a shorter elimination half life at 1.5 hours compared with adults. ${ }^{11}$ This increased clearance in children probably explains why no suppression of overnight urinary cortisol compared with placebo was found at any of the doses of budesonide studied when we have previously found suppressed overnight urinary cortisol with single doses of $1000 \mu \mathrm{g}$ in adults. ${ }^{12}$ The absence of significant dose related suppression of urinary free cortisol with budesonide has been demonstrated in a previous paediatric study with doses ranging from $200 \mu \mathrm{g}$ to $800 \mu \mathrm{g} /$ day. ${ }^{13}$ From first principles, greater systemic bioactivity effects would be predicted for a steroid which is more potent, has greater affinity and, when given by the inhaled route, has no first pass metabolism in the lung. ${ }^{1}$

In adult studies budesonide delivered by Nebuhaler causes increased adrenal suppression compared with metered dose inhaler alone. ${ }^{14}$ This presumably reflects the effect of enhanced lung bioavailability with the spacer which outweighs the effect of reduced oral bio- availability, at least for budesonide where first pass metabolism is $89 \%$. The present finding of adrenal suppression caused by single doses of inhaled fluticasone compared with budesonide, using a large volume spacer and mouth rinsing, further highlights the point that lung bioavailability is also the determinant of its systemic bioactivity in asthmatic children.

In conclusion, our study provides clear evidence of adrenal suppression with single doses of inhaled fluticasone propionate given by spacer to asthmatic children. It is likely that, with repeated dosing, the differences between fluticasone and budesonide would be greater ${ }^{15}$ due to the longer plasma half life and receptor binding affinity as well as enhanced systemic tissue retention for fluticasone than for budesonide. Further chronic dose ranging studies are now indicated to resolve this issue.

We are grateful to $\mathrm{Dr} J$ Cater for his assistance in the recruitment of patients for this study. Dr Clark is funded by a recruitment of patients for this st
grant from the Astra Foundation.

1 Lipworth BJ. New perspectives on inhaled drug delivery and systemic bioactivity. Thorax 1995;50:105-10.

2 Melchor R, Biddiscombe MF, Mak VHF, Short MD, Spiro SG. Lung deposition patterns of directly labelled salbuta$\mathrm{mol}$ in normal subjects and in patients with reversible airmol in normal subjects and in patients with

3 Harding SM. The human pharmacology of fluticasone propionate. Respir Med 1990;84(Suppl A): 25-9.

4 Ryrfeldt A, Anderson P, Edsbacker S, Tonnesson M, Davies D, Pauwels R. Pharmacokinetics and metabolism of budesonide, a selective glucocorticoid. Eur $\mathcal{F}$ Respir Dis 1963; (Suppl 122): 86-95.

5 English AF, Neate MS, Quint DJ, Sareen M. Biological activities of some corticosteroids used in asthma. Am $\mathcal{f}$ Respir Crit Care Med 1994;149(Suppl):A212

6 Phillips GH. Structure-activity relationships of topically active steroids: the selection of fluticasone propionate. Respir Med 1990;84(Suppl A):19-23.

7 Wurthwein G, Rehder S, Rohdewald P. Lipophilicity and receptor affinity of glucocorticoids. Pharm Ztg Wiss 1992; 4:161-7.

8 Hogger P, Rohdewald P. Binding kinetics of fluticasone propionate to the human glucocorticoid receptor. Steroids 1994;59:597-602.

9 Thorsson L, Dahlström K, Edsbacker S, Källen A, Paulson J, Wiren JE. Pharmacokinetics and systemic effects of inhaled flucticasone propionate in healthy subjects. $B r \mathcal{F}$ inhaled flucticasone propionate

10 Thorsson L, Edsbacker S, Conradson TB. Lung deposition of budesonide from turbohaler is twice that from a pressurised metered-dose inhaler (pMDI). Eur Respir f 1994; 7:1839-44.

11 Pedersen S, Steffensen G, Ekman I, Tonnesson M, Borga A. Pharmacokinetics of budesonide in children with asthma. Eur f Clin Pharmacol 1987;31:579-82.

12 Clark DJ, Grove A, Cargill R, Lipworth BJ. Comparative adrenal suppression with inhaled budesonide and fluticasone propionate in adult asthmatic patients. Thorax 1996; sone propion

13 Wolthers OD, Pedersen S. Measures of systemic activity of inhaled corticosteroids in children: a comparison of urine cortisol excretion and knemometry. Respir Med 1995; 89:347-9.

14 Toogood JH, Baskerville J, Jennings B, Lefcoe NM, Johansson SA. Use of spacers to facilitate inhaled corticosteroid treatment of asthma. Am Rev Respir Dis 1984;129:723-4.

15 Lonnebo A, Grahnen A, Ling-Anderson A, Brundin RM, Eckernas SA. A comparison of the effects on the HPA axis of single and repeated doses of inhaled fluticasone propionate and budesonide. Am $\mathcal{f}$ Respir Crit Care Med 1995; 151(Suppl):A375. 